$\xi_{3}=$

\title{
Artificial rubber mineralization by co-cultured bacterial strains
}

\author{
Manasa Muralidharan, VeenaGayathri Krishnaswamy* \\ Department of Biotechnology Stella Maris College, Chennai87, Tamilnadu, India \\ *Corresponding author E-mail:veenagayathri@yahoo.com
}

\begin{abstract}
Objective: This study involves the use Natural Rubber degrading Bacterial co-cultures isolated from rubber plantation soil for the degradation of Artificial Rubber.

Methods:Plate assay method and liquid assay method by using Mineral Salt Medium was followed for screening of bacteria for its capacity to mineralize Artificial rubber. Degradation was confirmed by Spectrophotometric and Fourier Transform Infra-Red (FTIR) studies. The co-cultures were able to utilize the artificial rubber which was confirmed by Spectrophotometric and FTIR studies.

Results: Bacterial cocultures have the capacity to mineralize artificial rubber. Mineralization was observed for 30 days and it was maximum (6.48 x 10-5) on the 20th Day. This was confirmed using SEM and FTIR.Further, these were applied on bioplastics and plastics to study their capacity to degrade them. It was able to degrade them as well which was confirmed using FTIR.

Conclusion: From current investigation, it can be concluded that the bacterial cocultures Bacillus cohnii and Brevundimonas naejangsanensis have the capacity to mineralize artificial rubber, plastics and bioplastics. Hence such isolated cocultures can be used in removal of artificial rubber, plastics and bioplastic wastes from the environment.
\end{abstract}

Keywords: Bacillus Cohnii; Brevundimonas naejangsanensis; Artificial Rubber, Plastics and Bioplastics; Mineralisation.

\section{Introduction}

In recent years, the waste disposal problem has spurred mounting interest in the biodegradability of polymers, especially when the public is voicing greater concern about protecting human health and preserving the quality of our environment. Rubber and plastics, for instance, that became an integral part of contemporary life, already formed a significant part of wastes in municipal landfills. Concerns regarding the environmental impact of solid wastes, recycling and composting options are expected to increase as landfill capacity decreases. Managing waste is thus a challenge facing the global community.

Today, plastics are utilized in more and more applications and they have become essential to our modern economy. The plastics industry has benefited from 50 years of growth with a year on year expansion of $8.7 \%$ from 1950 to 2012. In the medical and safety area, plastics are enabling major breakthroughs. The latest medical techniques use plastics to unblock blood vessels, develop artificial corneas or hearing devices to name but a few. Plastics are indispensable for protection equipment such as helmets, firemen suits or bullet proof jackets. Plastics have made it possible for us to push the limits and go further, faster and safer than we have dared to go before. (Aamer Ali Shah et al.2008)

Bioplastics are plastics derived from renewable biomass sources, such as vegetable fats and oils, corn starch, pea starch or microbiota. Bioplastics can be made from agricultural by products and also from used plastic bottles and other containers using microorganisms. Common plastics, such as fossil-fuel plastics (also called petrobased polymers), are derived from petroleum. Production of such plastics tends to require more fossil fuels and to produce more greenhouse gases than the production of biobased polymers (bioplastics). Some, but not all, bioplastics are designed to biodegrade. Biodegradable bioplastics can break down in either anaerobic or aerobic environments, depending on how they are manufactured. Bioplastics can be composed of starches, cellulose, biopolymers, and a variety of other materials. (Aamer Ali Shah et.al.2008).

As these plastics and rubber are not biodegradable, dumping of these causes grave threat to human health and environmental pollution. Thus it is the need of the hour to work on the degradation aspects of these polymers.

Hence the present study focuses on the mineralization of Artificial Rubber by co-cultured bacterial strains isolated from contaminated soil of rubber plantation area. Their growth conditions were optimized for maximum mineralization which were evaluated by FTIR studies and SEM observations. Further, the isolated cocultures were also applied in degradation of plastics and bioplastics.

\section{Materials and methods}

\subsection{Bacterial strains used to degrade artificial rubber}

The two bacterial strains, which were capable of degrading Natural rubber latex Bacillus cohnii, and Brevundimonas naejangsanensis were only used for the degradation of artificial rubber, plastics and bioplastics. (Manasa.M, VeenaGayathri k, 2016)

\subsection{Mineralization of artificial rubber by the co- cultured bacterial strains}

To study the mineralization of artificial rubber, latex glove was used as substrate. To $150 \mathrm{ml}$ of Mineral Salts Medium prepared after sterilization $3 \mathrm{~mm}$ of artificial rubber strips were added and co-cultured bacterial isolates were inoculated and incubated at $37^{\circ} \mathrm{C}$ in Orbital shaker at 100 RPM. Figure 1 shows the set-up. 
The strips were examined for mineralization by viewing in binocular light microscope, dark field microscope and SEM for a period of 30 Days. Further results were confirmed by analyzing the compounds released due to the mineralization of artificial rubber by performing FTIR spectroscopy.

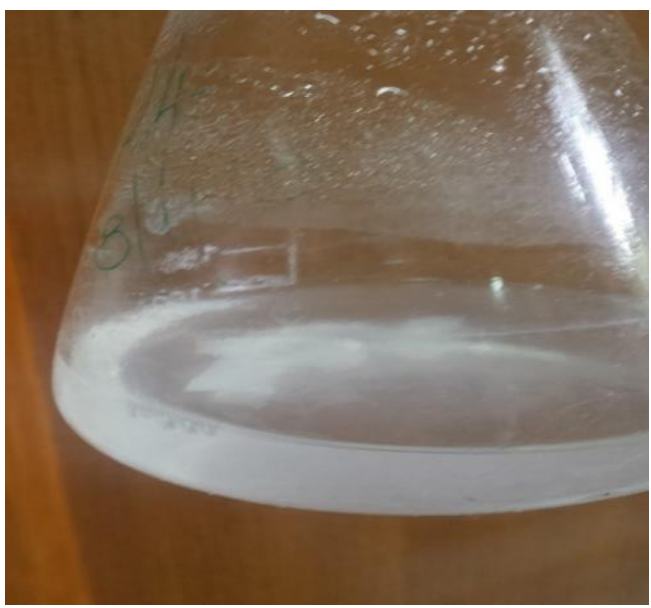

Fig. 1: Artificial Rubber Degradation in MSM.

\subsection{Analysis of rate of mineralization for the artificial rubber strips}

The rate of mineralization was determined by quantitative analysis of $\mathrm{BaCO}_{3}$. The mineral salts medium was sterilized and dispensed in bottles. Artificial rubber strips $(3 \mathrm{~mm})$ were given as the sole carbon source. Then the co-cultured bacterial isolates were inoculated. This was connected to the bottle containing $0.2 \mathrm{M} \mathrm{Ba}(\mathrm{OH})$ by using pipes. The bottles were sealed properly as shown in figure 2. The set up was incubated at room temperature. Quantitative estimation of $\mathrm{BaCO}_{3}$ was done by titrating it against $1 \mathrm{~N} \mathrm{HCl}$ (Warnekee et al.,) every $5^{\text {th }}$ day for a period of 30 days.

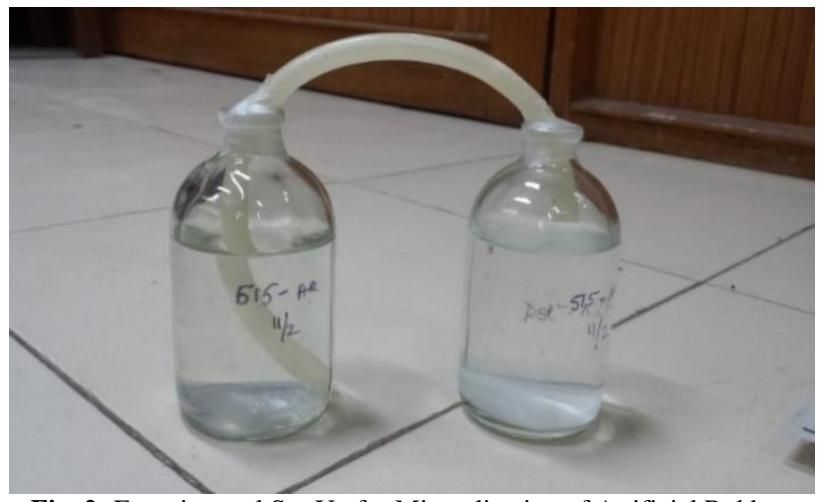

Fig. 2: Experimental Set-Up for Mineralization of Artificial Rubber.

\subsection{Confirmation using Schiff's reagent test}

Evidence for degradation and mineralization of cis-1,4polyisoprene rubber hydrocarbon chain was obtained by staining treated artificial rubber strips with Schiff's reagent. In a tightly stopper bottle, $10 \mathrm{ml}$ offuchsin reagent was added to a sample and kept for incubation for 10-30 minutes at room temperature. After 10-30 minutes excess amount of the reagent was discarded and $10 \mathrm{ml}$ of the sulfite solution was added in order to suppress nonspecific reactions. (Nayanashree et al., 2014)

\subsection{Evaluation of the products produced by mineraliza- tion of (poly-1,4-cis-isoprene)}

Chemical changes that arose directly on the artificial rubber surface as a result of the mineralization were determined using FTIR Spectroscopy. It was performed in Perkin Elmer Spectrum from IIT Chennai. The samples were studied in transmittance spectra in
IR range 4000 to $400 \mathrm{~nm}$ (Roy et al.,2005). The samples were also analyzed in SEM.

\subsection{Application of the bacterial strains for degrading plastics and bioplastics}

The efficiency of the bacterial isolates to degrade the plastics and bioplastic samples were studied. MSM broth was prepared in two conical flasks, sterilized and cooled. In this the bacterial isolates were inoculated and then $3 \mathrm{~mm}$ strips of bioplastics and plastics were added in each of the conical flasks. Degradation of the samples were studied using FTIR.

\section{Results}

\subsection{Mineralization of artificial rubber by the co- cultured bacterial isolates}

To study the application of Natural Rubber Mineralization, Artificial Rubber (latex gloves) was used as the substrate for further experiments. Latex gloves were studied for the breakdown of the compounds for the duration of 30 Days. During these 30 days mineralization rate was estimated every $5^{\text {th }}$ days. Figure 3 shows that mineralization was maximum $\left(6.48 \times 10^{-5}\right)$ on the $20^{\text {th }}$ Day. This was further confirmed by performing Schiff's reagent test, FTIR studies, and SEM images.

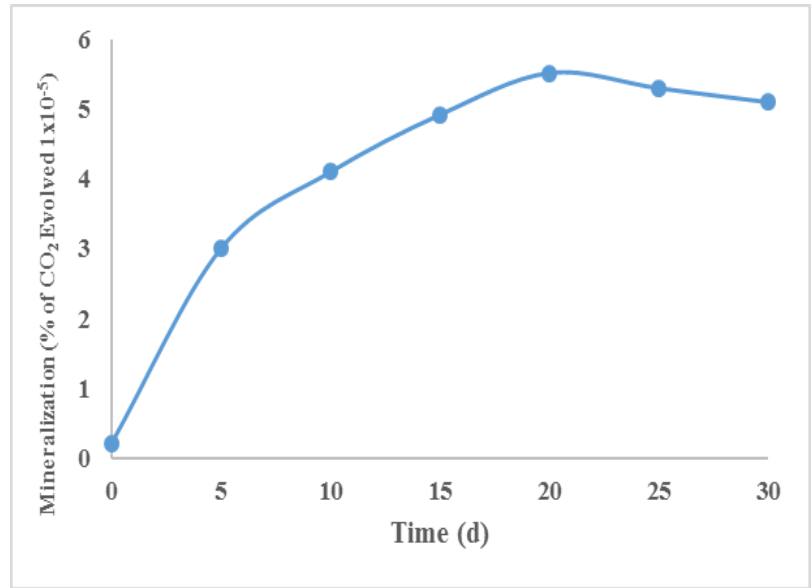

Fig. 3: Mineralization of Artificial Rubber Gloves.

\subsection{Schiff's reagent test}

Rubber sheets which were inoculated with co-cultured bacterial strains turned to purple color and there was no color formation in the control.Formation of purple color in the mineralized sample is due to the presence of aldehyde and ketone group which is produced as a result of degradation of cis-1, 4-polyisoprene units. Figure 4 shows the color change observed.

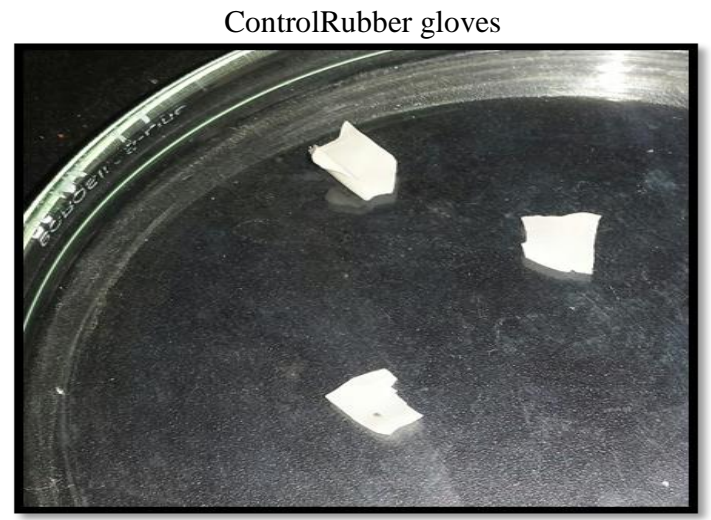

Mineralized Rubber gloves 


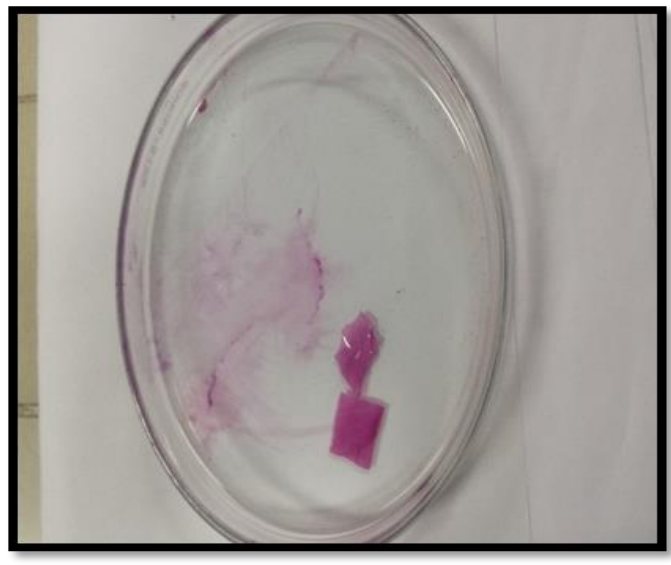

Fig. 4:Confirmation of Artificial Rubber Degradation by Schiff's Rea gentTest.

\subsection{FTIR results}

Artificial rubber which was utilized by the bacterial co-culture was studied for degradation products with FTIR analysis. Figure 5 shows the FTIR spectrum of Natural Rubber on Day 5 (A) and Day 30 (B).

(A)

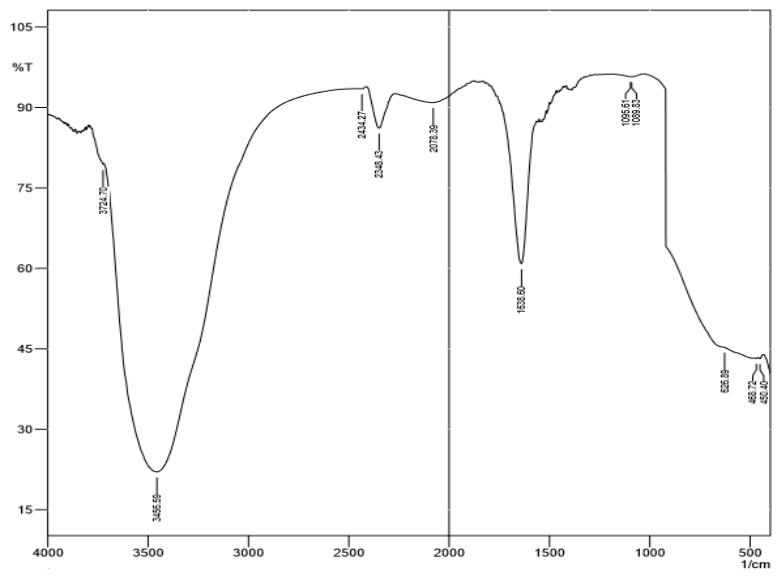

(B)

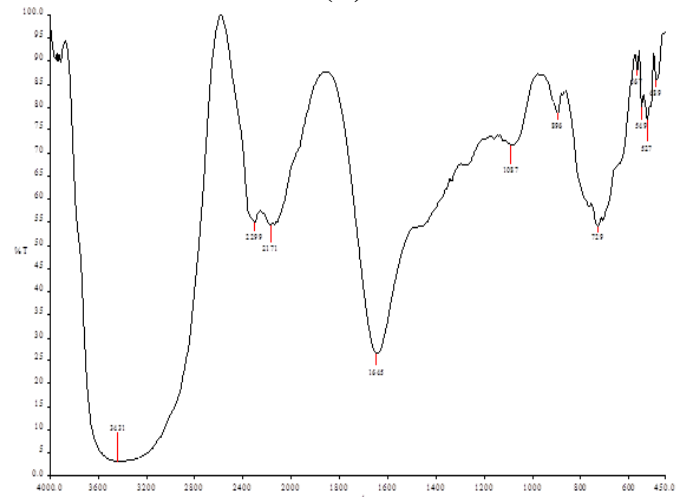

Fig. 5: Confirmation of Artificial Rubber Degradation by FTIR.

Artificial rubber was subjected for FTIR studies. Peaks were observed for $5^{\text {th }}$ and $30^{\text {th }}$ day at the wave length between $1638.60 \mathrm{~cm}^{-}$ ${ }^{1}$ and $1645 \mathrm{~cm}^{-1}, 1087 \mathrm{~cm}^{-1}$ respectively having $\mathrm{H}-\mathrm{C}=\mathrm{O}$. C-H stretch and $\mathrm{C}=\mathrm{O}$ stretch which indicates the presence of aldehydes and ketones, released as a result of artificial rubber degradation in the mineralised sample. Presence of these aldehyde and ketone group confirms artificial rubber degradation. (Nayanashreeet.al.,2013).

\subsection{Binocular microscope observation}

Artificial rubber was utilized by the bacterial co-culture was observed for degradation by observing under binocular microscopy. Figure 6 shows the distortion of Artificial Rubber under 100 times magnification. Figure 7 shows the distortion of artificial rubber under 400 times magnification.
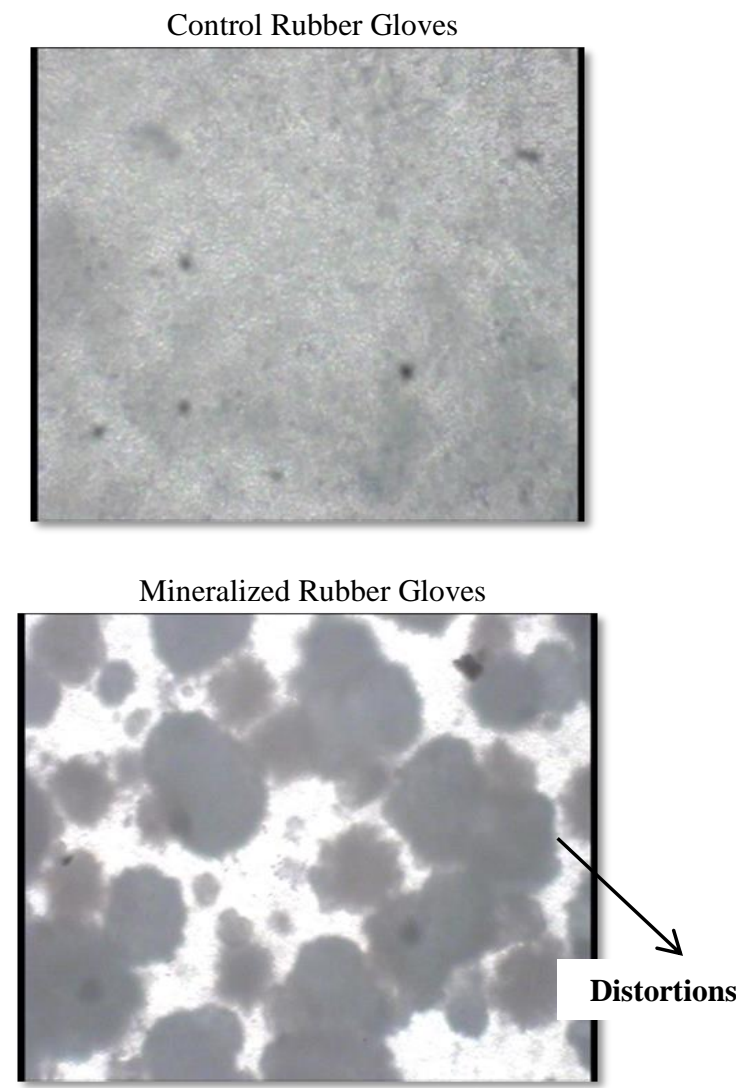

Fig. 6: Confirmation of Artificial Rubber Degradation by Binocular Microscope (100x).
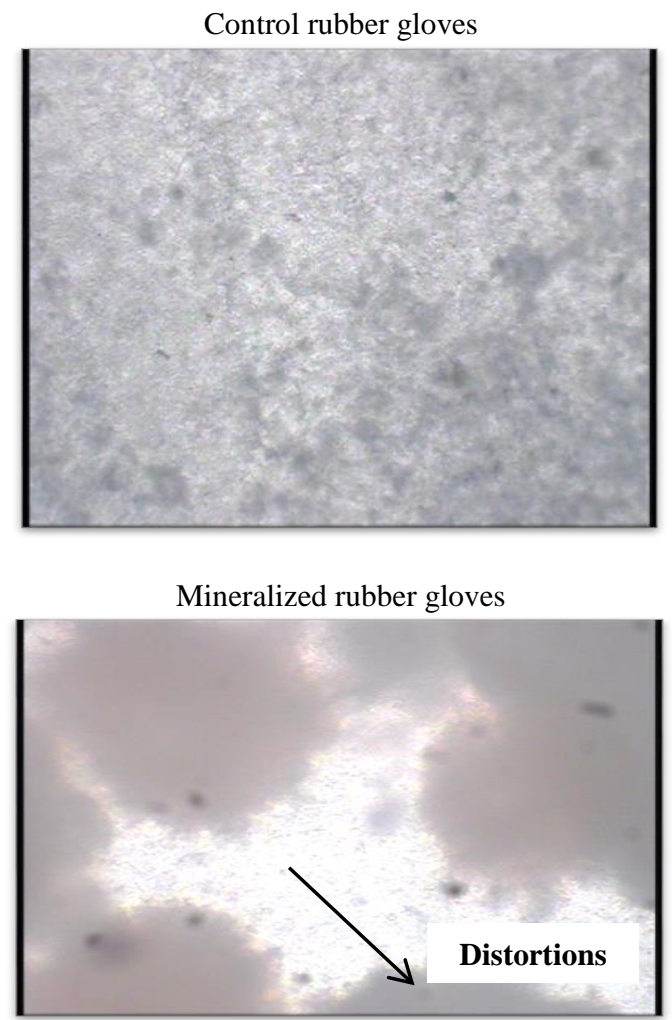

Fig. 7: Confirmation of Artificial Rubber Degradation by Binocular Microscope (400x). 


\subsection{Dark field microscopic observation}

Artificial rubber was utilised by the bacterial co-culture was observed for degradation by observing under dark field microscopy. Figure 8 shows control sample, Day 15 sample (A), Day 30 sample (B). It was observed that $30^{\text {th }}$ Day sample was observed to have more Distortions than $15^{\text {th }}$ Day Sample.

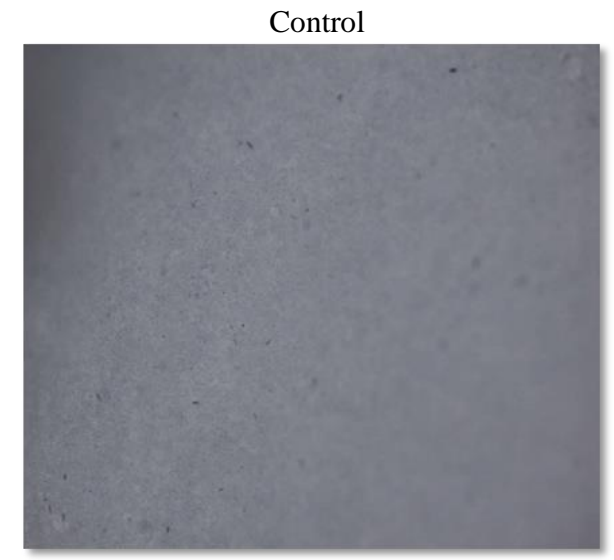

(A)

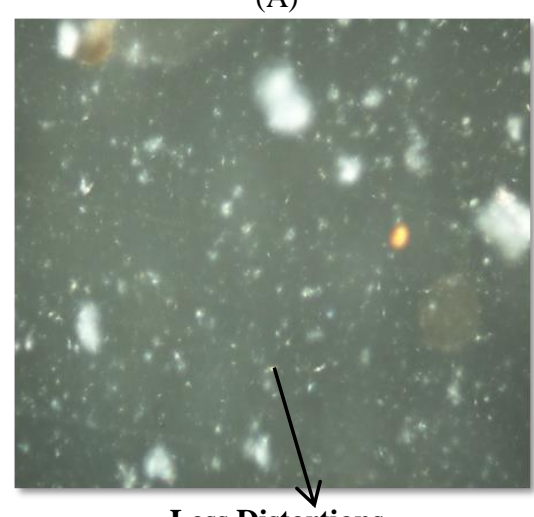

Less Distortions

(B)

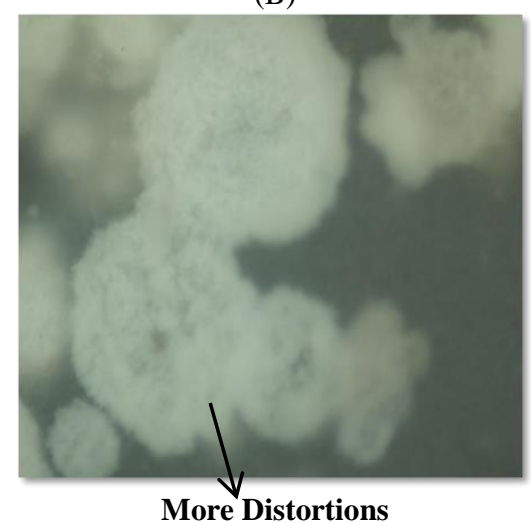

Fig. 8:Confirmation of Artificial Rubber Degradation by Dark Field Microscopy. (A) 15 Days - Rubber Gloves, (B) 30 Days- Rubber Gloves.

\subsection{SEM images}

Artificial rubber was utilised by the bacterial co-culture was observed for degradation by performing SEM. Figure 22 shows control sample, Day 9 sample (A), Day 30 sample (B). It was observed that $30^{\text {th }}$ Day sample was observed to have more Distortions and disintegration than $15^{\text {th }}$ Day Sample.

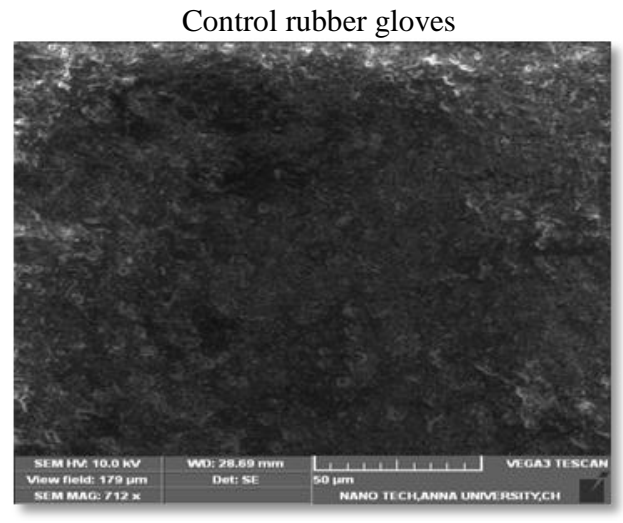

(A)

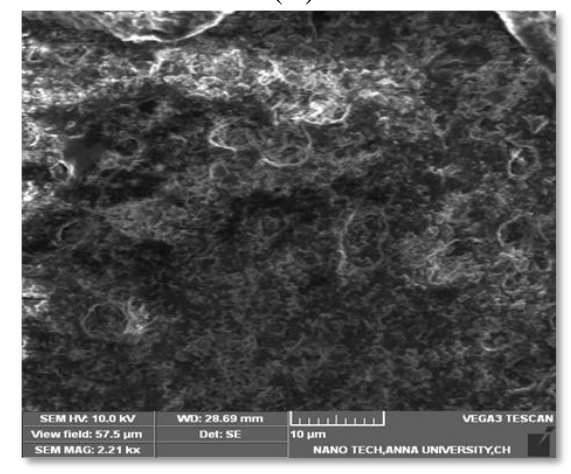

$10 \mu \mathrm{m}$

(B)

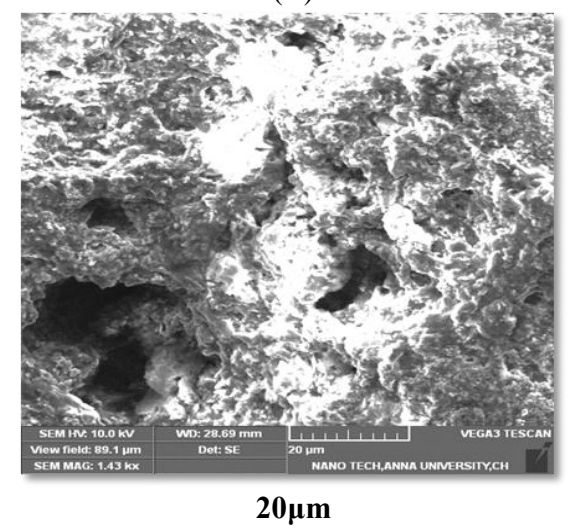

Fig.9: Confirmation of Artificial Rubber Degradation by SEM (A) 15 Days - Rubber Gloves, (B) 30 Days- Rubber Gloves

\subsection{Application of the co-cultured bacterial strains for the degradation of plastics}

To study the application of co-cultured Bacterial strains, plastics and bioplastics were used as the substrate for further experiments. Plastics and Bioplastics were studied for the breakdown of the compounds for the duration of 20 Days. During these 20 days to study the breakdown FTIR studies were performed

\subsection{FTIR results}

\subsubsection{Plastics degradation}

Plastics which was utilised by the bacterial co-culture was studied for degradation products with FTIR analysis. Figure 10 shows the FTIR spectrum of plastic degradation on Day 5 (A) and Day 30 (B). 
(A)

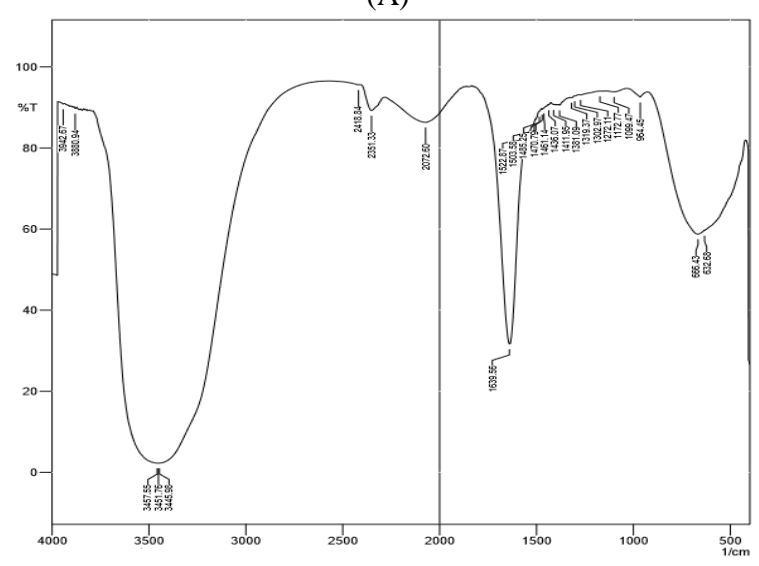

(B)

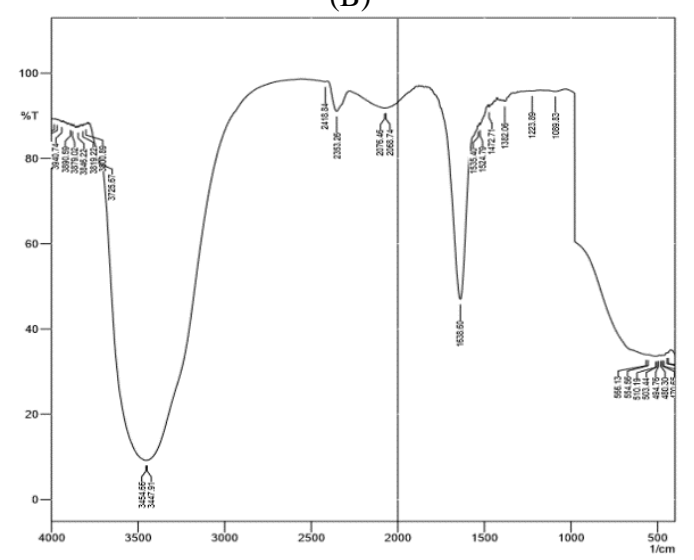

Fig. 10: Confirmation of Plastic Degradation by FTIR (A) 5 Days - Plastic Pieces, (B) 30 Days- Plastic Pieces

FTIR analysis of the $5^{\text {th }}$ and $20^{\text {th }}$ Day of plastic strips inoculated broth showed the following peaks as in Table 1 .

Table 1: Peaks Obtained by FTIR and Their Functional Groups Confirming Plastic Degradation

\begin{tabular}{ll}
\hline Day 5 & Day 20 \\
\hline $3000-3500 \mathrm{~cm}^{-1}-$ Amine & $3000-3500 \mathrm{~cm}^{-1}-$ Amine \\
$1639.56 \mathrm{~cm}^{-1}-$ Alkenes & $1638.60 \mathrm{~cm}^{-1}-$ Alkenes \\
$1400-1600 \mathrm{~cm}^{-1}-$ Carboxylic acids & $1400-1600 \mathrm{~cm}^{-1}-$ Carboxylic acids \\
\hline
\end{tabular}

\subsubsection{Bioplastic degradation}

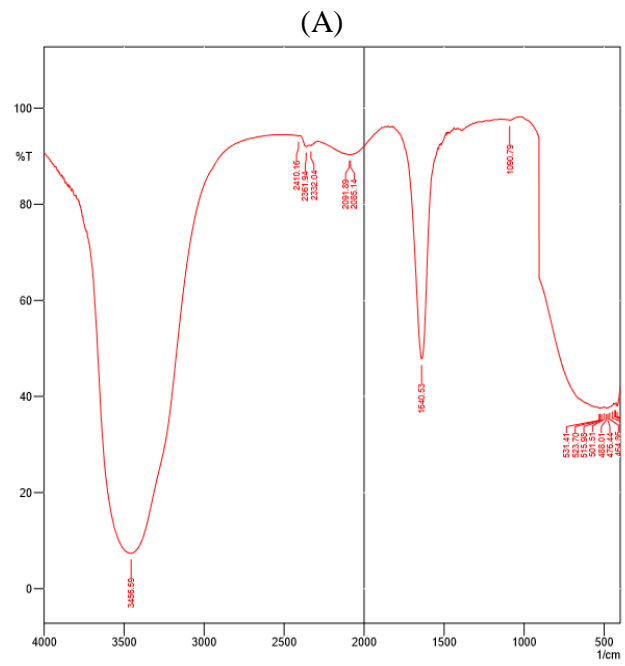

(B)

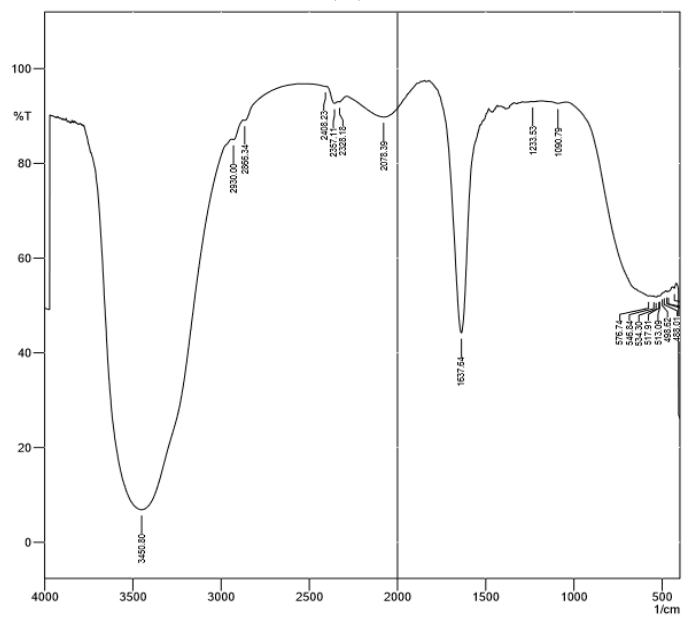

Fig. 11: Confirmation of Bioplastic Degradation by FTIR (A) 15 Days Bioplastic Pieces, (B) 30 Days- Bioplastic Pieces

Peaks obtained by FTIR and their functional groups confirming Bioplastic Degradation.

Table 2: Peaks Obtained by FTIR and Their Functional Groups Confirming Bioplastic Degradation

\begin{tabular}{ll}
\hline Day 5 & Day 20 \\
\hline $3000-3500 \mathrm{~cm}^{-1}-$ Amine & $3000-3500 \mathrm{~cm}^{-1}-$ Amine \\
$1639.56 \mathrm{~cm}^{-1}-$ Alkenes & $1638.60 \mathrm{~cm}^{-1}-$ Alkenes \\
$1000-1300 \mathrm{~cm}^{-1}-$ Esters & $1000-1300 \mathrm{~cm}^{-1}-$ Esters \\
$500-600-$ alkyl halides & $500-600-$ alkyl halides \\
\hline
\end{tabular}

Decomposition of urea units by release of ammonia contributes to the degradation of polyurethane. Sequentially the ester bonds of the urethane groups ( $\mathrm{H} 2 \mathrm{~N}-\mathrm{CO}-\mathrm{OR})$ could be broken by the hydrolytic effects of microbial esterases. PUR breakdown products were analysed by FTIR and reported that plastic and bioplastic degradation was caused by the hydrolysis of ester bonds Table 4 shows the peaks obtained. (Aamer Ali Shah et.al.,2008). Figure 24 shows the peaks obtained by the FTIR analysis.

\section{Discussion}

In the present scenario where one side usage of rubber products has increased the other side dumping of the used products have also increased. These wastes are degrading the environment and causing great threat to the environment. Physical and chemical techniques to solve the problem are causing even more threat instead of solving. Thus biological techniques of using microbes to degrade these complex proteins is the only way to solve the issue in a healthy way. Microbial degradation is mainly carried out by various microorganisms such as bacteria and fungi. In the present study an attempt was made to use the microbial strains which were capable of degrading Natural rubber latex for the degradation of artificial rubber, plastics and bioplastics.

Berekkaaetal.,(2005) have also used a technique to stain the artificial rubber strips with Schiff's reagent which indicated the presence of aldehydes in it. Processed artificial rubber was tested for mineralization and a few drops of Schiff's reagent was added to it. Appearance of purple color indicated the breakdown of double bonds of polyisoprene chains to form aldehyde thus confirming the test. This test was also performed in the present study and the presence of aldehydes through the desired color change was observed with the isolated bacterial strains, which proved the mineralization of artificial rubber strips.

In a study conducted by Aamer Ali Shah et al., (2008) bacterial isolates were made to degrade plastics and bioplastics as well. A number of aerobic and anaerobic microorganisms that degrade PHA, particularly bacteria and fungi, have been isolated from various environments. Aspergillusfumigatus, Comamonas sp., Pseudomonas lemoignei and Variovoraxparadoxus are among 
those found in soil, while in activated sludge Alcaligenesfaecalis and Pseudomonas have been isolated. Comamonastestosteroni has been found in seawater, Ilyobacterdelafieldii is present in the anaerobic sludge. PHA degradation by Pseudomonas stutzeri in lake water has also been observed.

Another bacterial strain Bacillus megaterium AF3, capable of degrading PHBV, was isolated from the soil and tested for degradation (Shah et al., 2007; Shah, 2007). In the present study two bacterial strains which were isolated and were identified to mineralize rubber were also observed to degrade plastics. The bacterial strains were as Bacillus cohnii and Brevundimonas naejangsanensis.

Aamer Ali Shah et al., (2008) obtained information on degradation by performing FTIR studies. Peaks were observed and were ranging around $2957 \mathrm{~cm}^{-1}$ (test) indicating the cleavage of $\mathrm{ClH}$ bonds and formation of $\mathrm{C}=\mathrm{C}$ at the region of $1400-1600 \mathrm{~cm}-1$. It was also observed that the decomposition of urea units by release of ammonia contributes to the degradation of polyurethane. Sequentially the ester bonds of the urethane groups (H2N-CO-OR) at $1715 \mathrm{~cm}^{-1}$ could be broken by the hydrolytic effects of microbial esterases. In the present study FTIR were performed and similar peaks were observed thus proving the breakdown of plastic compounds.

NidaKanwal et al.,(2015) performed a study to optimize some of the physical parameters for

degradation of tyre rubber by Bacillus sp. S10, in liquid mineral salt medium (MSM). This strain was previously isolated from the sewage sludge, collected from the sewage treatment plant, Rawalpindi. The optimum degradation of tyre rubber was observed at $\mathrm{pH} 7$ and $35^{\circ} \mathrm{C}$. Slide test with Schiff's reagent showed purple coloration, indicating the formation of aldehydes because of degradation by Bacillus sp. S10. Visible surface changes were observed through Scanning Electron Microscopy (SEM) analysis of treated tyre pieces incubated in MSM along with Bacillus sp. S10 with respect to untreated pieces as control. The degradation of tyre pieces was determined gravimetrically, by measuring the $\mathrm{CO}_{2}$ evolved through Sturm test. The amount of $\mathrm{CO}_{2}$ produced in case of test was found higher than the control samples. It is concluded from the results, that Bacillus sp. S10 has potential to degrade rubber tyres, hence it can be applied on spent rubber pieces under controlled environmental conditions.

\section{Conclusion}

Rubber products are widely used in our daily life. These products are made up of natural vulcanized rubber and other chemical additives. Due to vulcanization of the natural rubber these rubbers are very resistant to high temperature and persist in environment for very long time.Rubber materials have been increasingly used now days in different area after usage its disposal is a very big solid waste problem.It cannot be easily recycled due to the sulphur cross linking formed during vulcanization.If they are burnt they release enormous amount of carbon-di-oxide and some other gases which cause environmental pollution and contribute to the global warming.Rubber products such as balloon which are disposed in the natural environment are considered to be dangerous to wild animals if they are consumed by animals. One of the alternative ways to solve these problems is to subject these products to biodegradation. During the present study the isolated strains Bacillus cohnii and Brevundimonas naejangsanensis were found to mineralize both natural and artificial rubber. The isolated co-cultures were also applied for the degradation of plastics and bioplastics. Thus these strains can be used as an eco-friendly method for the degradation of these polymers. Future prospects of this study could be application of these strains in the contaminated soil containing rubber and plastic wastes.

\section{Acknowledgement}

I express my sincere thanks to Department of Biotechnology, Stella Maris College and for providing all facilities for successful completion of the project. It has been a great learning experience working under my guide Dr. K VeenaGayathri, Assistant Professor, Department of Biotechnology, Stella Maris College.My heartfelt gratitude to my Parents for their blessings, moral support and constant encouragement. I sincerely thank each and every one who had been associated with the completion of this work directly or indirectly.

\section{References}

[1] Aamer Ali Shah., FariahHaasan, Abdul Hameed., Safia Ahmed (2008) Biodegradation of plastics: A Comprehensive Review, Biotechnology Advances p 246-265.

[2] AbdElLatifHeshama, Nadia H. Mohamedb, Mady A. Ismail , and Ahmed A.M. Shoreit Microbiology, 2015, Vol. 84, No. 3, pp. 351358. (C) Pleiades Publishing, Ltd., 2015

[3] BerekaaM.M,Barakaat A., El-Sayeed S.M. and El-Aassar S. A. 2005 Degradation of Natural Rubber by Achromobacter sp. NRB and Evaluation of culture conditions, Polish Journal of Microbiology. Volume 54, No. 1,p 55-62.

[4] Cherian E. and Jayachandran K. (2009). Microbial degradation of natural rubber latex by a novel species of Bacillus sp. SBS 25 isolated from soil, International Journal of Environmental Research. Vol. 3, No. 4, p. 599-604.

[5] Cui Q., Wang L., Huag Y., Liu Z. and Goodfellow M. (2005), “Nocardiajiangxiensis sp. nov.andNocardiamiyunensis sp. nov., isolated from acidic soils". International Journal of Systematic and Evolutionary Microbiology. $\quad$ 55: 1925.http://dx.doi.org/10.1099/ijs.0.63644-0.

[6] Desmond Threadingham, Werner Obrecht, Wolfgang Wieder, Gerhard Wachholz and RüdigerEngehausen. (2011) "Rubber, 3. Synthetic Rubbers, Introduction and Overview" in Ullmann'sEncyclopedia of Industrial Chemistry. Weinheim. http://dx.doi.org/10.1002/14356007.a23_239.pub5.

[7] Ibrahim E. M. A., Arenskotter M., Luftmann H. and Steinbuchel A. (2006). "Identification of poly (cis-1,4- isoprene) degradation intermediates during growth of moderately thermophilicactimycetes on rubber and cloning of a functional ICP homologue from Nocardiafarcinica strain EI". Applied Environ. Microbiology. 72: 33753382.http://dx.doi.org/10.1128/AEM.72.5.3375-3382.2006.

[8] Lee K.M, D.F.Gimore, and M.J.Huss (2005), Fungal Degradation of the Bioplastics PHB, Journal of Polymer and the environment. Vol 13 no. , DOI 10.1007/s10924-005-4756-4.

[9] Manasa. M, VeenaGayathri K, (2016), Mineralisation of natural rubber (poly cis 1-4 isoprene) by co-cultured bacterial strains isolated from rubber plantation area,International Journal of Biological Research, 4(1) (2016) 1-9, http://dx.doi.org/10.14419/ijbr.v4i1.5552.

[10] Nayanashree.G, Thippeswamy.B and Krishnappa.M(2014)Natura Rubber Biodegradation by Cladosporiumfulvum and Enzymes responsible for Biodegradation International Journal of Advanced Research, Volume 2, Issue 4 ,1206-1212.

[11] Nayanashree.G, Thippeswamy.B, Krishnappa.M (2014) Enzymatic studies on Natural rubber biodegradation byBacilluspumilus, International Journal of Biological Research, 2 (2) 44-4.

[12] Nayanashree.G and Thippeswamy.B, (2013) Natural Rubber Degradation ByAspergillusniger and Penicillium sp. International Journal of Recent Scientific Research Vol. 4, Issue, 9, pp.13371341.

[13] Rose K. and Steinbuchel A. (2005) "Biodegradation of natural rubber and related compounds: Recent insights into a hardly understood catabolic capability of microorganisms". Applied and Environmental Microbiology. 2803 2812.http://dx.doi.org/10.1128/AEM.71.6.2803-2812.2005.

[14] Rose K., Tenberge K. B. and Steinbuchel A. (2005). Identification and characterization of genes from Streptomyces sp. strain K30 responsible for clear zone formation on natural rubber latex and poly (cis-1, 4-isoprene) rubber degradation. Bio macromolecules. vol. 6, no. 1 , p. $180-188$.http://dx.doi.org/10.1021/bm0496110.

[15] Roy R.V., Das M., Banerjee R. and Bhowmick A. K. (2006). Comparative studies on cross linked and uncross linked natural rubber biodegradation by Pseudomonas sp. Bio resource Technology. vol. 
97, no. $18, \quad$ p. 2485-

2488.http://dx.doi.org/10.1016/j.biortech.2005.09.024.

[16] Seo S. J., Keum Y. S., Harada R. M. and Li Q. X. (2007). Isolation and characterization of bacteria capable of degrading polycyclic aromatic hydrocarbons (PAHs) and organophosphorus pesticides from PAH-contaminated soil in Hilo, Hawaii. Journal of Agricultural and Food Chemistry. vol. 55, no. 14, p. 53835389.http://dx.doi.org/10.1021/if0637630.

[17] Shey J., Imam S. H. Glenn G. M. and Orts W. J. (2006). Properties of baked starch foam with natural rubber latex. Industrial Crops and Products. vol. 24, no. 1, p. 34 40.http://dx.doi.org/10.1016/j.indcrop.2005.12.001.

[18] SirimapornWatcharakul, KamontamUmsakul, Brian Hodgson, WannapaChumeka, VarapornTanrattanakul. (2012). Electronic Journal of Biotechnology. vol.15, No.1

[19] SorenWarneke, Matthias Arenskotter, Klaus B. Tenberge and Alexander Steinbuchel. (2007). Bacterial degradation of poly (trans-1, 4isoprene)(guttapercha). Microbilogy. 153, 347356.http://dx.doi.org/10.1099/mic.0.2006/000109-0.

[20] Tanrattanakul V. and Chumeka W. (2009). Effect of potassium persulfate on graft copolymerization and mechanical properties of cassava starch/natural rubber foams. Journal of AppliedPolymer Science. vol. 116, no. 1, p. 93 105.http://dx.doi.org/10.1002/app.31514.

[21] Wang Z. F., Peng Z., Li S. D., Lin H., Zhang K. X., She X. D. and Fu X. (2009). The impact of esterification on the properties of starch/natural rubber composite. Composites Science andTechnology. vol. 69, no. 11-12, p. 1797 1803.http://dx.doi.org/10.1016/j.compscitech.2009.04.018.

[22] Warneke S., Arenskotter M., Tenberge K. B. and Steinbuchel A (2007). Bacterial degradation of poly (trans-1, 4-isoprene) (Guttapercha). Microbiology. vol. 153, no. 2, p. $347-$ 356.http://dx.doi.org/10.1099/mic.0.2006/000109-0.

[23] Yamamura H., Hayakawa M., Nakagawa Y., Tamura T., Kohno T., Komatsu F. and Limura Y. (2005), "Nocardiatakedensissp. nov., isolated from moat sediment and scumming activated sludge". International Journal of Systematic and Evolutionary Microbiology. 55: 433-436.http://dx.doi.org/10.1099/ijs.0.63189-0.

[24] Yu L., Dean K. and Li L. (2006). Polymer blends and composites from renewable resources. Progress in Polymer Science. vol. 31
no.
576

602.http://dx.doi.org/10.1016/j.progpolymsci.2006.03.002.

[25] Ziaullah Shah, Aamer Ali Shah, Abdul Hameed and FarihaHasan. (2009). Effect of pretreatments on enhanced degradation of polyisoprene rubber by newly isolated Bacillussp. Strain S10. Journal of the Chemical Society of Pakistan. Vol. 31, No. 4: 638-646. 